\title{
How nanotechnology can enhance docetaxel therapy
}

\author{
This article was published in the following Dove Press journal: \\ International Journal of Nanomedicine \\ 6 August 2013 \\ Number of times this article has been viewed
}

\section{Li Zhang \\ Na Zhang}

School of Pharmaceutical Science, Shandong University, Shandong Province, People's Republic of China

Correspondence: Na Zhang

School of Pharmaceutical Sciences,

Shandong University, 44 Wen

Hua Xi Road, Ji'nan, 2500 I2, Shandong

Province, People's Republic of China

Tel +86053188382015

Fax +86 053 I 88382548

Email zhangnancy9@sdu.edu.cn
Abstract: Docetaxel has been recognized as one of the most efficient anticancer drugs over the past decade; however, its poor water solubility and systemic toxicity have greatly limited its clinical application. In recent decades, the emergence of nanotechnology has provided new drug delivery systems for docetaxel, which can improve its water solubility, minimize the side effects and increase the tumor-targeting distribution by passive or active targeting. This review focuses on the research progress in nanoformulations related to docetaxel delivery - such as polymer-based, lipid-based, and lipid-polymer hybrid nanocarriers, as well as inorganic nanoparticles - addressing their structures, characteristics, preparation, physicochemical properties, methods by which drugs are loaded into them, and their in vitro and in vivo efficacies. Further, the targeted ligands used in the docetaxel nanoformulations, such as monoclonal antibodies, peptides, folic acid, transferrin, aptamers and hyaluronic acid, are described. The issues to overcome before docetaxel nanoformulations can be used in clinical and commercial applications are also discussed.

Keywords: docetaxel, nanotechnology, nanoformulations, target delivery systems, cancer therapy

\section{Introduction to docetaxel}

Docetaxel (DTX) is a second-generation taxoid cytotoxic agent which has been proven to have significant antitumor activity against various human cancers. In 1980s, Pierre Potier at the National Center for Scientific Research in France discovered DTX during his work on improving the production of Taxol. ${ }^{1}$ DTX was prepared by semisynthesis from 10-deacetylbaccatin-III, an inactive precursor compound isolated from a renewable resource, the needles of the European yew tree, Taxus baccata. As shown in Figure 1, DTX is structurally similar to paclitaxel except for the tert-Butyl carbamate ester in the side chain of phenylpropionate and the hydroxyl functional group on carbon 10. DTX is more water-soluble than paclitaxel due to its different chemical structure. $^{2}$

The antitumor mechanism of action for DTX is hyperstabilistation of microtubules. ${ }^{3}$ DTX binds preferentially to $\beta$-subunit protein of tubulin in the microtubules and promotes assembly of tubulin into stable microtubules while simultaneously inhibiting their depolymerization. The formation of stable microtubule bundles disrupts the normal dynamic equilibrium between polymerization and depolymerization within the microtubule system and leads to cell cycle arrest at the G2/M phase and, ultimately, cell death. Although DTX has an antitumor mechanism of action similar to that of paclitaxel, DTX shows a higher affinity for the microtubule binding site and 


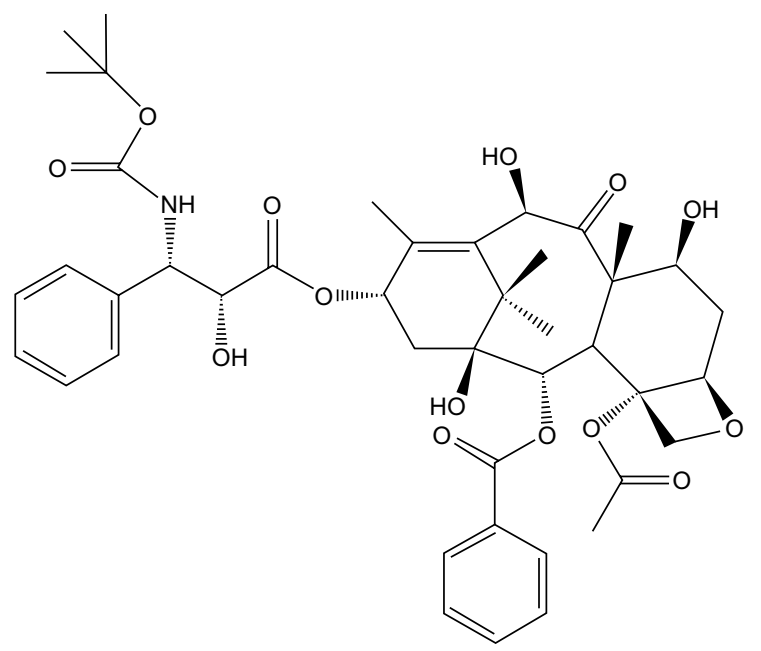

Docetaxel

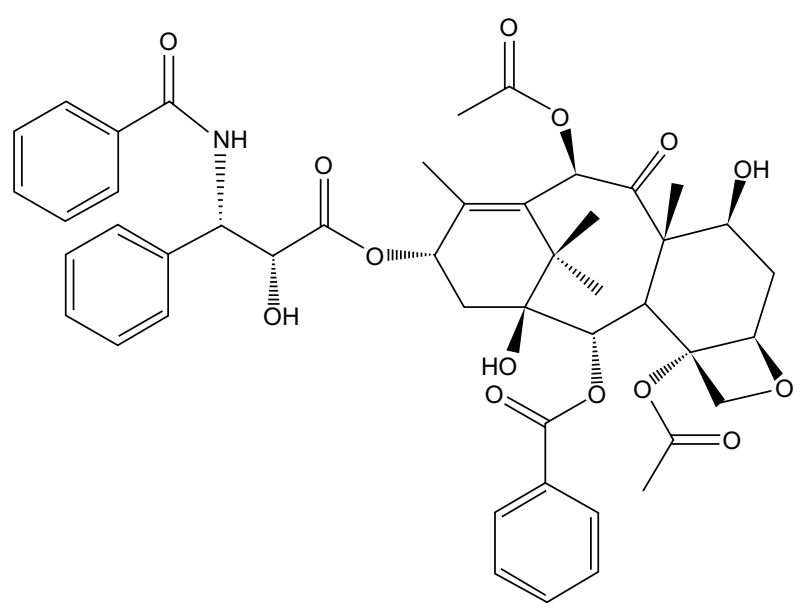

Paclitaxel

Figure I Chemical structure of docetaxel (top) and paclitaxel (bottom).

is approximately twice as potent as paclitaxel. ${ }^{4}$ Apart from inhibiting the depolymerization of microtubules, DTX also has anti-angiogenic efficacy and induces the expression of numerous genes involved in cellular processes. ${ }^{2,5}$ Therefore, DTX shows significant antitumor activity against a broad spectrum of human tumors.

\section{Current issues: safety, efficacy and delivery}

The clinical application of DTX is limited greatly owing to its poor water solubility. Currently, the only available commercial formulation of DTX is Taxotere ${ }^{\circledR}$ (SanofiAventis, Bridgewater, NJ, USA), which is composed of $40 \mathrm{mg} / \mathrm{mL}$ DTX and $1040 \mathrm{mg} / \mathrm{mL}$ Tween 80 (polysorbate $80 ;$ P80) and requires further dilution with $13 \%$ ethanol before administration. Taxotere was first approved for the treatment of anthracycline-refractory metastatic breast cancer in 1996, and later for the treatment of platinum-refractory non-small-cell lung cancer, hormone refractory prostate cancer, head and neck cancer, advanced gastric cancer, and ovarian cancer. ${ }^{6-8}$ Despite its wide use for the treatment of various cancers, Taxotere is associated with serious side effects, including acute hypersensitivity reactions, cumulative fluid retention, neurotoxicity, febrile neutropenia, nail toxicity, myalgia, nasolacrimal duct stenosis and asthenia. ${ }^{9-11}$ Phase II studies of Taxotere in the treatment of various solid tumors showed that the most frequent adverse effects were alopecia (81\%), grade III-IV leucocytopenia of short duration (66\%), skin reactions (52\%), and hypersensitivity reactions $(26 \%) .{ }^{12}$ These side effects are attributable to either DTX as a cytotoxic agent or the presence of P80..$^{2,13}$

Stability data showed that the premix solutions are stable for 8 hours at room temperature or under refrigeration, and diluted infusion solution are stable for 4 hours at room temperature. ${ }^{14}$ The main reason for the short storage time is the potential risk of precipitation of the infusion solution during storage, which are affected by various factors such as insufficient mixing of the premix solutions, temperature, and excessive agitation. ${ }^{15}$

To overcome the side effects and improve anticancer efficacy of Taxotere, much attention has been focused on the design of an alternative delivery system for DTX. The emergence of nanotechnology has been of benefit to research in DTX delivery systems because it offers the advantages of unique size, drug solubilization, passive targeting by enhanced permeability and retention (EPR) effect, controlled drug release, and further modification for long circulation in vivo, escape from reticuloendothelial system (RES), and tumor-specific targeting. Currently, the most studied nanoformulations for DTX delivery include polymeric nanoparticles (NPs), drug-polymer conjugates, micelles, liposomes, dendrimers, and inorganic NPs.

In this paper, the research progress of these nanoformulations related to DTX delivery are reviewed, covering their structures, characteristics, preparation, physicochemical properties, drug loading methods, and the in vitro and in vivo efficacies.

\section{Nanoformulations currently in development \\ Polymer-based nanoformulations}

Since Helmut Ringsdorf proposed the concept of polymer-drug conjugates in 1975 and the subsequent success of N-(2-hydroxypropyl) methacrylamide (HPMA) 
copolymer-doxorubicin conjugate (named "PK1") in clinical trials, polymer-based nanocarriers have gained increasing attention for their abilities to increase drug solubility, enhance drug-loading capacity, improve therapeutic efficacy, and reduce systemic toxicity. ${ }^{16,17}$ Currently, widely researched polymers for DTX delivery include poly(ethylene glycol) (PEG), poly(glutamic acid) (PGA), poly(lactic-co-glycolic acid) (PLGA), HPMA copolymers, and polysaccharides (eg, chitosan, cyclodextrin). ${ }^{18-21}$ To ensure renal elimination, the molecular mass of nonbiodegradable polymers such as PEG and HPMA copolymers should be less than $40 \mathrm{kDa}$. Drugs can be loaded in polymer-based nanocarriers by physical encapsulation or chemical conjugation. The former nanocarriers are known as "polymeric micelles" or "polymeric NPs", and the latter as "polymer-drug conjugates" (Figure 2). Representative examples of studies on polymer-based nanoformulations for DTX are listed in Table 1.

\section{Polymeric micelles}

Micelles are colloidal dispersions with spontaneously formed core-shell structure smaller than $100 \mathrm{~nm}$. Traditional micelles with surfactants usually have relatively high critical micelle concentration (CMC) and are unstable upon strong dilution. Recently, polymeric micelles generally formed by the self-assembly of amphiphilic block copolymers in aqueous solution have drawn increasing attention due to better thermodynamic stability in physiological solutions with lower CMC, fairly narrow size distribution, higher solubilization capacity, and a slower rate of dissociation allowing a longer drug retention time and greater accumulation at the target sites. ${ }^{22}$ Elsabahy et al synthesized poly(ethylene oxide)-block-poly(styrene oxide) (PEO-b-PSO) and
PEO-b-poly(butylene oxide) (PEO-b-PBO), which can selfassemble to form micelles in water with a highly viscous core at low CMC $(<10 \mathrm{mg} / \mathrm{L}) .{ }^{23}$ These polymers improved the solubility of DTX by $0.7 \%-4.2 \%$ and efficiently protected DTX from degradation. Mikhail and Allen coupled DTX to poly(ethylene glycol)-b-poly( $\varepsilon$-caprolactone) (PEG-b-PCL) copolymer, which formed the copolymer-drug conjugate PEG-b-PCL-DTX with a low CMC of $14 \mathrm{mg} / \mathrm{L} .{ }^{24}$ When DTX was encapsulated in PEG-b-PCL-DTX micelles, an 1,840 -fold increase in the aqueous solubility of the drug was achieved. ${ }^{24}$

\section{Polymeric NPs}

Polymeric NPs have been widely used as drug delivery vehicles owing to their small sizes, controlled drug release properties, prolonged circulation time, reduced toxicity and surface functionalizations. ${ }^{25}$ BIND-014 (BIND Therapeutics, Cambridge, MA, USA), a polymeric nanoparticle of DTX based on PEG-PLGA copolymers with controlled release property, is undergoing a Phase I trial to determine the maximum tolerated dose and assess its dose-limiting toxicities. ${ }^{26,27}$ BIND-014 is an active nanoformulation targeted to prostatespecific membrane antigen, which is abundantly expressed on the surface of cancer cells and new blood vessels of solid tumors. $^{5,28}$ In preclinical cancer models, BIND-014 was shown to deliver up to 20 times more DTX to tumors than an equivalent dose of Taxotere. ${ }^{29}$ DTX-PNP, a polymeric NP developed by Samyang Pharmaceuticals (Seoul, Korea), was comprised of a mixture of monovalent metal salts of poly(lactic acid), amphiphilic diblock copolymers and the drug. ${ }^{27,30}$ A Phase I clinical trial of this formulation for the treatment of various solid malignancies is currently under-

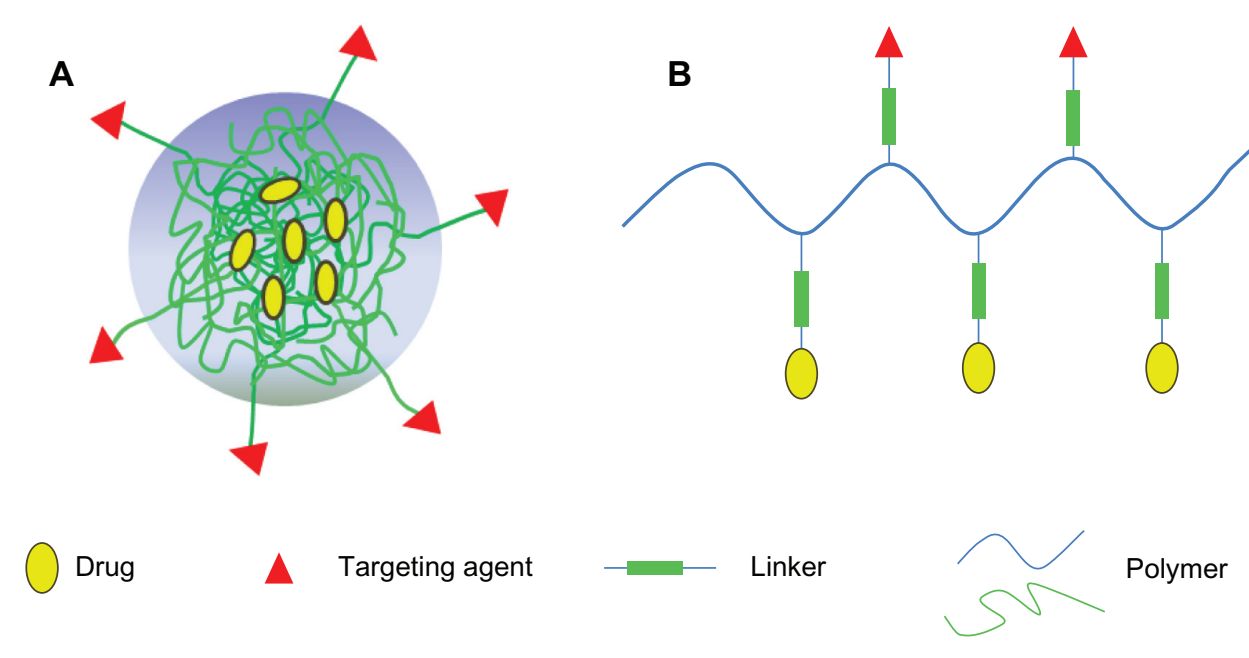

Figure 2 Schematic representations of polymeric nanoparticles (A) and polymer-drug conjugates (B). 
Table I Representative examples of studies on polymer-based nanoformulations for docetaxel (DTX)

\begin{tabular}{|c|c|c|c|c|c|}
\hline Name & Polymer & $\begin{array}{l}\text { Drug loading } \\
\text { method }\end{array}$ & $\begin{array}{l}\text { Type } \\
\text { of nanoformulations }\end{array}$ & Targeted ligand & Ref \\
\hline $\begin{array}{l}\text { Mixed MPP/Pluronic }{ }^{\circledR} \\
\text { micelles }\end{array}$ & $\begin{array}{l}\text { MPEG-PLA and Pluronic } \\
\text { copolymers }\end{array}$ & Encapsulation & Micelle & - & 18 \\
\hline $\mathrm{TPGS}_{2 \mathrm{k}}$ micelles & Vitamin E TPGS & Encapsulation & Micelle & Folic acid & 45 \\
\hline Nanoxel-PM ${ }^{T M}$ & mPEG-PDLLA & Encapsulation & Micelle & - & 46 \\
\hline DTX-HGC nanoparticles & $\begin{array}{l}\text { Cholanic acid-modified glycol } \\
\text { chitosan }\end{array}$ & Encapsulation & Nanoparticle & - & 21 \\
\hline PBCA-PEG-ZOL NPs & PEG-PBCA & Encapsulation & Nanoparticle & Zoledronic acid & 47 \\
\hline $\begin{array}{l}\text { DTX-loaded HA-CE/P85- } \\
\text { based nanoparticles }\end{array}$ & HA-CE and Pluronic & Encapsulation & Nanoparticle & Ceramide & 48 \\
\hline LMWC-DTX conjugates & Low molecular weight chitosan & Conjugation & Conjugate & - & 35 \\
\hline Cellax ${ }^{\mathrm{TM}}$ & PEG-carboxymethylcellulose & Conjugation & Conjugate & - & 34 \\
\hline DTX-HPMA conjugates & HPMA copolymer & Conjugation & Conjugate & - & 20 \\
\hline DTX-P80-PPI dendrimers & Poly(propyleneimine) & Encapsulation & Dendrimer & Polysorbate 80 & 44 \\
\hline
\end{tabular}

Abbreviations: HA-CE, hyaluronic acid-ceramide; HGC, hydrophobically modified glycol chitosan; HPMA, N-(2-hydroxypropyl)methacrylamide; LMWC, low molecular weight chitosan; mPEG-PDLLA, methoxy-poly(ethylene glycol)-block-poly(D,L-lactide); MPEG, methoxy poly(ethylene glycol); MPP, methoxy-poly(ethylene glycol)-poly (lactide) polymer; P80, polysorbate 80; PEG-PBCA, polyethylene glycolylated polybutyl cyanoacrylate; PLA, poly(lactide); PPI, poly(propyleneimine); TPGS 2 , D-a-tocopheryl polyethylene glycol succinate 2000; ZOL, zoledronic acid; NPs, nanoparticles.

way in Korea. In a recent report, Conte et al developed NPs of amphiphilic block copolymers of poly( $\varepsilon$-caprolactone) (PCL) and poly(ethylene oxide) (PEO) for co-delivery of DTX and zinc-phthalocyanine $(\mathrm{ZnPc})$ as a potential dual carrier system for the combination of chemotherapy and photodynamic therapy (PDT). ${ }^{31}$ The ZnPc/DTX-loaded NPs were determined to have greater cell cytotoxicity and antitumor activity than DTX-loaded NPs, thus demonstrating a combined effect of both DTX and ZnPc.

\section{Polymer-drug conjugates}

Over the past few decades, polymer-drug conjugates have been attracting remarkable interest as drug delivery systems with great potential. Drugs can be conjugated to water-soluble polymers or amphiphilic block copolymers via biodegradable ester or amide bonds, which can increase water solubility, reduce elimination from the RES, provide a long circulation time, improve pharmacokinetics, and promote tumor targeting through EPR effect. ${ }^{32}$ Compared with polymeric NPs, polymer-drug conjugates have the advantages of higher drug loading, enhanced stability and better control over drug release kinetics. Moreover, the linkers between polymers and drugs could be designed to trigger drug release.$^{17}$ Promising results from clinical trials with polymer-drug conjugates such as PGA-paclitaxel, HPMA-doxorubicin and PEG-irinotecan have been drawn increasing attention to these conjugates. ${ }^{17}$

A PEG-DTX derivative (NKTR-105; Nektar Therapeutics, San Francisco, CA, USA) has entered Phase I clinical trial on patients with solid tumors including hormone-refractory. ${ }^{33}$ In a recent article by Ernsting et al, the development a polymer conjugate (Cellax $\left.{ }^{\mathrm{TM}}\right)$ composed of acetylated carboxymethylcellulose, DTX, and PEG was reported. ${ }^{34}$ The results of in vitro and in vivo studies demonstrated that the conjugate improved the pharmacokinetics, biodistribution and antitumor efficacy of DTX over Taxotere, with reduced toxicity. Lee et al prepared a conjugate with DTX and low molecular weight chitosan (LMWC) via a cleavable linker. ${ }^{35}$ The water solubility of DTX was increased by approximately 200 -fold after conjugation with LMWC. The LMWC-DTX conjugate had antitumor efficacy comparable to DTX but was revealed to have much lower subacute toxicity. Etrych et al conjugated DTX with HPMA via a pH sensitive spacer that was stable under physiological conditions ( $\mathrm{pH}$ 7.4) and hydrolytically degradable in mildly acidic environments ( $\mathrm{pH} \sim 5$ ) to achieve prolonged drug circulation time in blood and drug release in target cells.$^{20}$

\section{Dendrimers}

Dendrimers are monodispersed macromolecules characterized by regular and extensively branched three-dimensional structures. Dendrimers were first reported by Vögtle and co-workers in $1978,{ }^{36}$ but their unique potential did not begin to generate widespread interest until the early 1990 s. $^{37}$ Dendrimers comprise an initiator core, an interior layer consisting of repeating units (generations), and exterior end groups. ${ }^{38}$ Dendrimer synthesis approaches can be generally divided into divergent or convergent, depending on the direction of synthesis. The former approach, introduced by Tomalia, ${ }^{39}$ begins in the central core and continues to the periphery, while the latter, developed by Hawker and Fréchet, ${ }^{40}$ proceeds from the surface inward to the interior core. Drugs can be encapsulated in the void spaces 
between branches or linked to the surface functional groups of dendrimers covalently or non-covalently.

Dendrimers have been widely used for the delivery of both hydrophobic and hydrophilic drugs, nucleic acids and imaging agents due to their attractive properties such as well-defined size and molecular weight, monodispersity, multivalency, number of available internal cavities, high degree of branching, and greater number of surface functional groups. ${ }^{41-43}$ A preclinical trial of dendrimer-DTX performed by Sylvania Platinum Ltd has reported that the water solubility, circulation time and efficacy in treating breast cancer in animals were better than those of Taxotere. ${ }^{2}$ A Phase I/II clinical trial of the dendrimer has been approved. ${ }^{2}$ Gajbhiye and Jain developed P80-anchored poly(propyleneimine) (PPI) dendritic nanoconjugate for delivery of DTX targeted to brain tumor. ${ }^{44}$ The DTX-P80-PPI dendrimers showed better antitumor efficacy and higher penetration in brain tumor than both DTX-PPI and free DTX.

\section{Lipid-based nanoformulations}

Lipid-based nanoformulations are composed of biocompatible lipids and surfactants, with drugs encapsulated in a lipid core or adsorbed on the NP surface. Examples include liposomes, solid lipid nanoparticles (SLNs), nanostructure lipid carriers (NLCs), and lipid-based-nanosuspensions (LNSs) (Figure 3). Natural and synthetic biocompatible lipids can be divided into those that are solid or liquid. Solid lipids contain glycerides (eg, tripalmitin and glyceryl monostearate), fatty acids (eg, stearic acid), sterides (eg, cholesterol), and waxes (eg, microcrystalline wax). Commonly used liquid lipids include medium-chain triglyceride oil, oleic acid, soybean oil, and olive oil. Owing to lipid materials and biomimetic structure, lipid-based nanoformulations have been widely used for DTX delivery as they offer good biocompatibility, effectively increasing DTX's water solubility, significantly improve drug membrane permeability, and allow sustained drug release. ${ }^{49,50}$ Table 2 summarizes some representative lipid-based nanoformulations for DTX delivery that have been recently reported.

Liposomes are closed spherical vesicles consisting of an aqueous core and one or more lipid bilayers. The aqueous core can be used for encapsulation of water-soluble drugs, whereas the lipid bilayers entrap hydrophobic or amphiphilic compounds. Drugs can be loaded into liposomes by one of four ways: (1) by preparing liposomes in an aqueous solution saturated with soluble drugs, (2) using organic solvents and solvent exchange mechanisms, (3) via $\mathrm{pH}$ gradient methods; (4) or through ammonium sulfate gradient methods. ${ }^{51} \mathrm{To}$ escape RES uptake after intravenous injection, PEGylated liposomes (known as "stealth liposomes") were developed for reducing clearance and prolonging circulation half-life. Currently, a Phase I trial of liposome-encapsulated DTX (LE-DT), ${ }^{52}$ developed by NeoPharm, Inc, (Lake Forrest, IL, US), is underway, as is a Phase II trial of another nonPEGylated liposomal DTX. ${ }^{2}$ However, the applications of liposomes have been limited due to problems such as low encapsulation efficiency, rapid leakage of water-soluble
A

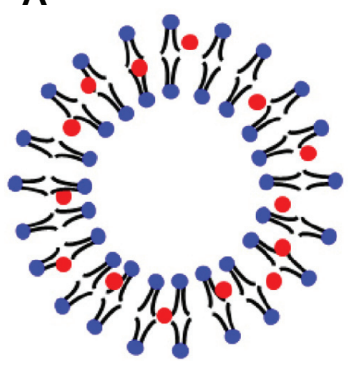

C

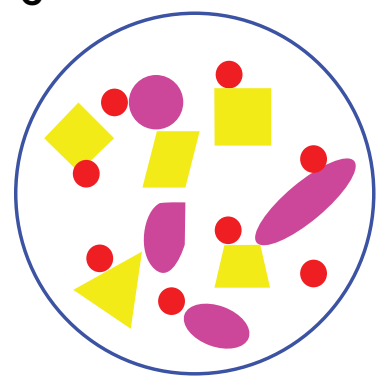

B

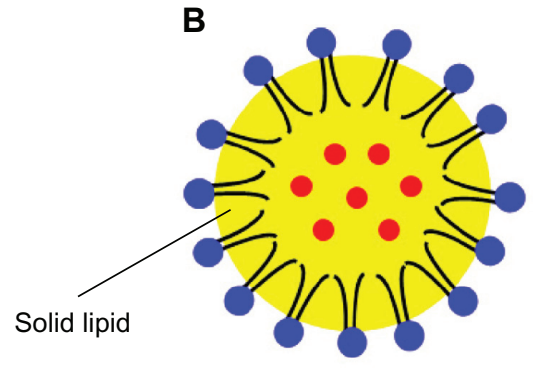

D

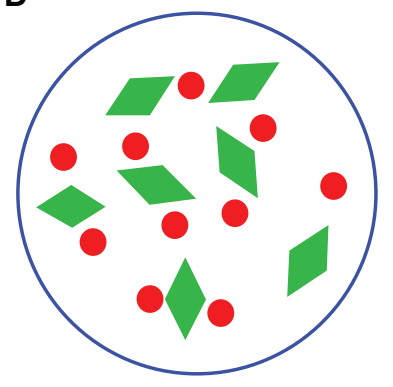

Drug

Phospholipid

Surfactant

Liquid lipid

Solid lipid

Figure 3 Simple schematics of liposomes (A), solid lipid nanoparticles (B), nanostructure lipid carriers (C), and lipid-based nanosuspension (D). 
Table 2 Summary of lipid-based nanoformulations for docetaxel (DTX) delivery in recent reports

\begin{tabular}{|c|c|c|c|c|}
\hline Name & $\begin{array}{l}\text { Type } \\
\text { of nanoformulation }\end{array}$ & $\begin{array}{l}\text { Drug loading } \\
\text { method }\end{array}$ & Targeted ligand & Ref \\
\hline Vitamin E TPGS-coated liposomes & Liposomes & Encapsulation & - & 63 \\
\hline $\begin{array}{l}\text { DTX-QDFA for co-delivery of DTX } \\
\text { and QDs }\end{array}$ & Theranostic liposomes & Encapsulation & FA & 64 \\
\hline DTX-loaded hepatoma-targeted SLNs & SLNs & Encapsulation & Galactose & 56 \\
\hline HD-SLNs & SLNs & Encapsulation & Beta-hydroxybutyrate & 65 \\
\hline Double-targeted NLCs & NLCs & Encapsulation & Anti-VEGFR-2 antibody & 58 \\
\hline FA-DTX-NLCs & NLCs & Encapsulation & FA & 66 \\
\hline Targeted DTX- LNS & LNS & Encapsulation & FA & 62 \\
\hline
\end{tabular}

Abbreviations: DTX-QDFA, docetaxel loaded liposomes prepared with quantum dots loading and folate targeting; FA, folic acid; HD-SLNs, betreliesoxybutyric acidgrafted docetaxel-loaded solid lipid nanoparticles; LNS, lipid-based nanosuspension; NLC, nanostructured lipid carrier; QD, quantum dot; SLN, solid lipid nanoparticle; TPGS, D-alpha-tocopheryl polyethylene glycol 1000 succinate; VEGFR, Vascular endothelial growth factor receptor.

drugs in the presence blood components, and poor storage stability. ${ }^{53,54}$

SLNs were introduced at the beginning of the 1990s as an alternative delivery system to liposomes, emulsions and polymeric NPs. SLNs possess various advantages, including increased physical stability, protection of drugs against degradation, and controlled drug release; in addition, they do not require the use of organic solvents in preparation, they can be easily produced and sterilized on a large scale, and are biodegradable, biocompatible, and have low toxicity. ${ }^{55}$ SLNs are prepared by exchanging the liquid lipid (oil) of emulsions with a lipid that is solid at room temperature as well as at (human) body temperature. Surfactants are added to stabilize the lipid dispersion. The two main methods of SLNs production are high pressure homogenization and microemulsion. Xu et al prepared DTX-loaded hepatoma-targeted solid lipid nanoparticles (tSLNs) with galactosylated dioleoylphosphatidyl ethanolamine for the treatment of locally advanced and metastatic human hepatocellular carcinoma. ${ }^{56}$ The particle size and encapsulation efficiency of the tSLN was $\sim 120 \mathrm{~nm}$ and $>90 \%$, respectively. Further, sustained release of the tSLNs was observed over 30 days in vitro. The tSLN showed better antitumor efficacy and reduced toxicity compared with Taxotere in a murine model bearing hepatoma.

NLCs have been presented as an improved generation of lipid NPs consisting of solid lipid matrices and spatially incompatible liquid lipids developed from the SLNs system. The liquid lipids can disrupt the crystal lattice structure of SLNs and increase the number of imperfections in matrix, thereby increasing the drugloading capacity and minimizing drug expulsion during storage compared with SLNs. Moreover, the drug release profile can be controlled by varying the composition and amount of the lipid. ${ }^{57}$ Results of research on a DTXloaded double-targeted NLC modified with anti-vascular endothelial growth factor receptors (VEGFR)-2 antibody suggest that the double-targeted NLC could deliver DTX to both the tumor vasculature cells and the tumor cells, and inhibited tumor growth effectively. ${ }^{58}$

LNSs, first developed by our group, are colloidal dispersions with dispersed nanosized drug particles ranging between 100 and $500 \mathrm{~nm}$ in an aqueous medium and stabilized against self-aggregation by lipid-derived surfactants. ${ }^{59}$ Compared with other lipid-based nanocarriers, LNSs have no drug leakage problems, are easily produced on a large-scale, have a high drug-loading capacity, are physically stable over the long-term, have low toxicity, and are suitable for drugs that are insoluble in both water and oil. As such, LNSs are one of the most potential nanoformulations. ${ }^{59}$ They can be produced through high pressure homogenization, precipitation, emulsion/microemulsion template, media milling, and dry co-grinding. ${ }^{60}$ In nanosuspensions, drugs are in crystalline state and have a nanoscale particle size, thereby increasing the saturation solubility and dissolution rate of poorly soluble drugs, and improving bioavailability. ${ }^{61}$ Our group has prepared a DTX-loaded-LNS(DTX-LNS), a poly(ethylene glycol)-modified docetaxel-lipid-based nanosuspension (pLNS), and a folate-targeted docetaxel-lipid-based nanosuspension (tLNS) by high pressure homogenization for DTX delivery. ${ }^{59,62}$ The particle sizes of the nanosuspensions were about $200 \mathrm{~nm}$ and they are physically stable over 3 months at $4^{\circ} \mathrm{C} \pm 2{ }^{\circ} \mathrm{C}$ and $25^{\circ} \mathrm{C} \pm 2{ }^{\circ} \mathrm{C}$. The folate-targeted DTX-LNS showed high antitumor efficacy, prolonged blood circulation, and much less toxicity in B16 tumor-bearing mice than Duopafei $^{\circledR}$ (Qilu Pharmaceutical Co, Ltd , Jinan, People's Republic of China).

\section{Lipid-polymer hybrid nanoformulations}

Lipid-polymer hybrid nanoparticles are composed of a solid polymeric core and a lipid shell. ${ }^{67}$ As shown in Figure 4, the 


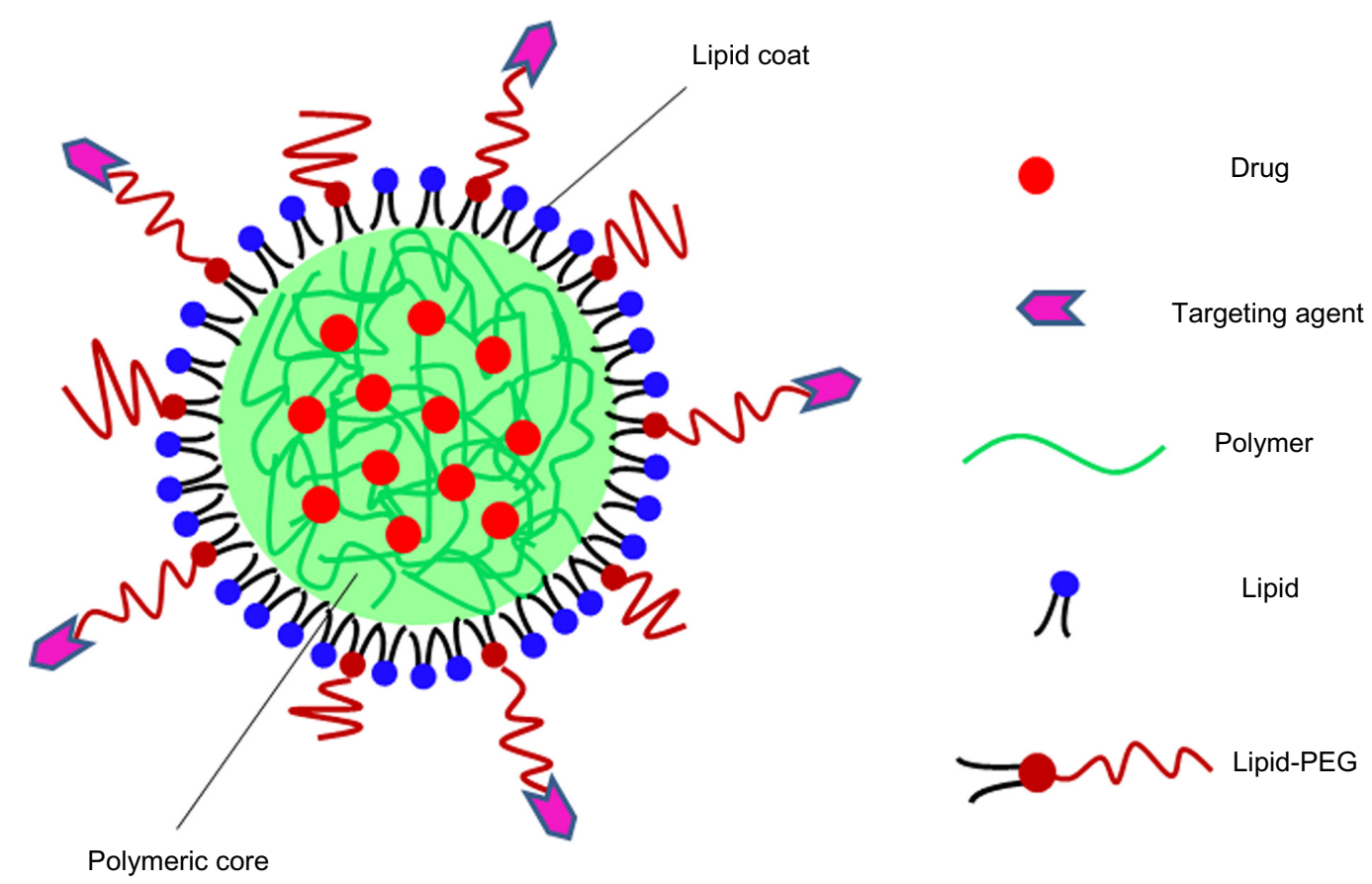

Figure 4 Lipid-polymer hybrid nanoparticle. The polymeric core, with the drug loaded into it, is surrounded by a lipid/lipid-poly(ethylene glycol) (lipid-PEG) monolayer. The nanoparticle is functionalized by conjugating ligands onto the PEG.

polymeric core, which is loaded with water or oil-soluble drugs, is surrounded by a lipid/lipid-PEG monolayer, and the NP can be further functionalized by conjugating ligands onto the PEG chains. It has been claimed that lipid-polymer hybrid NPs combine the highly biocompatibility of lipid-based nanoformulations and the structural integrity provided by polymeric NPs, overcoming the drawbacks of them. ${ }^{68}$ Lipid-polymer hybrid NPs have exhibited that their particle size can be well-controlled, high drug-loading, high stability, controlled drug release, and the ability to be functionalized for long circulation half-life and targeted drug delivery. ${ }^{69,70}$

Three methods of preparing lipid-polymer hybrid NPs have been reported. The first method is a two-step process involving production of the polymeric NPs followed by coincubation of these with lipid vesicles (or lipid films) to form the lipid-shell by electrostatic interactions. ${ }^{71}$ However, this method reduces drug encapsulation efficiency, especially for highly water-soluble drugs. The second method involves a simpler technology, combining nanoprecipitation and a self-assembly technique in a single step, with the drug and polymer dissolved in a water-miscible solvent first, then added to an aqueous phase containing lipids, which leads to the co-precipitation of the drug and polymer to form NPs with self-assembled lipids on their surface. ${ }^{72}$ This method is only suitable for the encapsulation of those drugs that are water insoluble and soluble in the water-miscible solvent The third approach is a modified emulsification method, with lipids replacing traditional surfactants as the stabilizer. In this method, the drug, polymer, and lipid are first dissolved in a water-immiscible solvent then subsequently emulsified in an aqueous phase under sonication, resulting in the formation of hybrid NPs. ${ }^{73}$

Liu's research group synthesized a system of targeted lipid-shell and polymer-core nanoparticles (TLPNPs) with a PLGA core and mixed lipid monolayer shell of 1,2dilauroylphosphatidylocholine (DLPC), 1,2-distearoyl-snglycero-3-phosphoethanolamine-N-[methoxy(polyethylene glycol)-2000] (DSPE-PEG $2 \mathrm{k}$ ), and 1,2-distearoyl-snglycero3-phosphoethanolamine- N-[folate(polyethylene glycol)5000] (DSPE-PEG ${ }_{5 \mathrm{k}}$-FOL). ${ }^{72}$ DLPC was employed to stabilize the NPs in the aqueous phase, and DSPE-PEG ${ }_{2 k}$ was used to escape from recognition by the RES - thus increasing the systemic circulation time of the NPs - while the DSPE-PEG ${ }_{5 \mathrm{k}}-\mathrm{FOL}$ provided NPs with tumor-targeting ability. The TLPNPs showed a sustained and controlled release profile for DTX in vitro and higher cellular uptake efficiency than the non-targeted formulation in MCF7 cells with overexpressed folate receptors. Further, in vitro cytotoxicity studies demonstrated that the TLPNPs were 50.91\% more effective than the non-targeted formulation and $93.65 \%$ more effective than Taxotere. 


\section{Inorganic nanoparticles}

Mesoporous silica nanoparticles (MSNs) have attracted growing interest in the last decade as an efficient drug delivery system. ${ }^{74,75}$ Compared with conventional organic carriers, MSNs have unique properties including tunable particle size and morphology, tailored mesoporous structure, uniform and tunable pore size, high chemical and mechanical stability, high surface area and pore volume, high drug-loading capacity and facile surface functionalization. ${ }^{76,77}$ By modification of their surface, MSNs can be functionalized with a controlled drug release characteristic or targeted delivery capability. ${ }^{78,79}$

Li et al reported PEGylated silica nanorattles (SNs) loaded with DTX (SN-PEG-DTXs) via electrostatic absorption for liver cancer therapy. ${ }^{80}$ The SN-PEG-DTXs showed higher cytoxicity in HepG2 human liver cancer cells, greater antitumor activity in the marine hepatocarcinoma 22 subcutaneous model than Taxotere, and lower systematic toxicity. Chen et al prepared double mesoporous silica-shelled nanostructure (called “HMSs@ $\mathrm{mSiO}_{2}$ ”) with hierarchical pore-size distributions, diverse pore orderings in separate but adjacent shells, and enlarged surface area/pore volume for the delivery of DTX..$^{81}$ The HMSs@ $\mathrm{mSiO}_{2}$ exhibited high loading capacity, satisfactory biocompatibility, significant uptake and enhanced anticancer efficiency due to the presence of large interior hollow space.

Gold nanoparticles (AuNPs) (ranging in size from 1 to $150 \mathrm{~nm}$ ) have emerged as a useful platform for biomedical applications in the delivery of gene, imaging agents and drugs. ${ }^{82,83}$ François et al encapsulated DTX into PEGylated AuNPs (creating "AuNPs-DTX") for vectorization to cancer cells. ${ }^{84}$ The AuNPs-DTX were 2.5 -fold and $\sim 1.5$-fold more efficient against MCF7 cells and against HCT15 cells, respectively, than DTX alone due to the AuNPs drug encapsulation.

\section{Targeted delivery}

Targeted delivery has been developed for DTX to increase drug distribution in tumor tissues, reduce side effects in normal tissues, and improve therapeutic index. Drug targeting can be classified into two types: passive and active targeting. Passive targeting, depending on the EPR effect, means the accumulation of macromolecular agents and nanocarriers in solid tumor tissues, which have unique pathophysiological characteristics, including extensive angiogenesis, hypervasculature, defective vascular architecture, and an impaired lymphatic drainage/recovery system..$^{85}$ The EPR effect was first reported by Matsumura and Maeda in 1986, ${ }^{86}$ and has thus now become a gold standard in anticancer drug delivery designing. ${ }^{87}$ Active targeting process proceeds after the passive accumulation of nanocarriers in tumors, to achieve the further selective targeting delivery of drugs to tumor cells, through specific interactions, such as antigen-antibody and ligand-receptor binding. ${ }^{88}$ Following, we focus on the application of active targeting in DTX nanoformulations.

\section{Monoclonal antibodies}

Monoclonal antibodies are one of the most well-known targeting ligands for drug delivery due to their high specificity and affinity to target antigens..$^{89,90}$ Herceptin $^{\circledR}$, the clinical formulation of trastuzumab produced by Genetech, Inc (South San Francisco, CA, USA), is the monoclonal antibody against human epidermal growth factor receptor 2 , which is overexpressed in invasive breast cancers. ${ }^{91}$ Liu et al conjugated Herceptin on PLGA-PEG/PLGA NPs using a post-conjugation strategy for efficient targeted delivery of DTX. ${ }^{11}$ In SK-BR-3 breast cancer cells overexpressing human epidermal growth factor receptor 2, the non-antibody conjugated NPs demonstrated virtually no uptake, while significantly increased cellular uptake efficiency was observed with the Herceptin-conjugated NPs. The percentage of the NPs endocytosed by the cells was almost proportionally increased to the surface density of the ligand. VEGFRs are overexpressed in both various tumor cells - including gastric, breast, melanoma, carcinoma cervicis, non-small-cell lung cancer - and tumor neovasculature in situ. An anti-VEGFR-2 antibody modified DTX-loaded targeted NLC (tNLC) was developed by our group for tumor-specific delivery and therapy by double-targeting (tumor cells- and vascular-targeting) strategy. ${ }^{58}$ The tNLC showed better antitumor efficacy in cytotoxicity studies on HepG2, A549 and mouse B16 cells, and in a murine model bearing B16 cells than Duopafei and the non-targeted NLC. Cellular uptake and biodistribution studies indicated that the better antitumor efficacy of tNLC was attributed to the increased accumulation of the drug in both the tumor and tumor vasculature.

\section{Peptides}

As targeting ligands, peptides are small molecules compared with monoclonal antibodies that can be efficiently chemically synthesized and have high specificity. ${ }^{92}$ In a recent report, the asparagine-glycine-arginine (NGR) peptide, which can target to aminopeptidase $\mathrm{N}$ (CD13) overexpressed on tumor vascular endothelial cells, was conjugated to PEG-b-PLGA polymeric micelles for targeted delivery of DTX.${ }^{93}$ The higher uptake by CD13-overexpressed tumor cells and greater antitumor activities in vivo of the NGR conjugated micelles were confirmed. 
Octreotide, one of the most extensively studied neuropeptide somatostatin analogs, showed high binding affinity to the positive tumor cells of somatostatin receptors. Zhang et al prepared octreotide-modified DTX-loaded PEG-b-poly(lactide) (PLA) polymeric micelles (OCT-PM-DTXs) and achieved enhanced intracellular delivery efficiency via receptor-mediated endocytosis in NCI-H446 cells and higher retardation of tumor growth after intravenous injections into a xenograft NCI-H446 tumor model. ${ }^{94}$ The arginine-glycine-aspartic (RGD) peptide, binding to $\alpha_{\mathrm{v}} \beta_{3}$ integrin with high affinity, which is highly expressed in neovascular endothelial cells, has been widely used in various DTX delivery system such as monomethoxy PEG-block-poly(L-lactide-co-2-methyl-2-carboxyl-propylene carbonate) (MPEG-b-P(LA-co-MCC))/DTX conjugate, ${ }^{95}$ RGD grafted DTX liposomes (RGD-PEG-LP-DC), ${ }^{92}$ and HPMA copolymer-DTX-RGDfK conjugate. ${ }^{97}$

\section{Folic acid}

Folic acid (FA) is a well-studied targeting ligand that has been widely used for tumor-specific delivery of drugs. It has a high affinity to folate receptors that are frequently overexpressed in various cancer cells, including ovary, brain, kidney, breast, colon, and lung cancers, but are expressed only to a low extent in normal cells. ${ }^{98}$ Moreover, FA is highly stable, nonimmunogenic, inexpensive and of small molecular size. ${ }^{99} \mathrm{Mi}$ et al prepared FA-conjugated vitamin $\mathrm{ETPGS}_{2 \mathrm{k}}$ micelles for DTX-targeted delivery. ${ }^{45}$ Zhao et al developed a folate-poly (PEG-cyanoacrylate-co-cholesteryl cyanoacrylate)-modified DTX-loaded NLC (FA-DTX-NLC) to achieve a long blood circulating effect and targeting characteristics. ${ }^{66}$ The tLNS prepared by our group using folate as targeting ligands, which is suitable for large-scale production and has high specificity to cancer cells overexpressing folate receptors, was produced by the lipid incorporation method. ${ }^{100}$

\section{Aptamers}

Aptamers have rapidly become a novel and powerful class of targeting ligands for drug delivery systems in recent years because of their fascinating properties, which include ease of selection and synthesis, high binding affinity and specificity, low immunogenicity, and versatile synthetic accessibility. ${ }^{101,102}$ Aptamers are short single-stranded DNA, RNA, or modified nucleic acids that can fold into complex three-dimensional structures and specifically bind to their targets. ${ }^{103}$ Aptamers can be selected from randomly synthesized oligonucleotide libraries through the systematic evolution of ligands by exponential enrichment. ${ }^{104}$ Aptamers have been demonstrated to have more specific and higher affinity for the intended target than other ligands (eg, antibodies). ${ }^{105}$

Cheng et al reported DTX-encapsulated NPs formulated with PLGA-b-PEG copolymer and surface functionalized with the A10 RNA aptamers that recognize the extracellular domain of the prostate-specific membrane antigen, a well characterized antigen expressed on the surface of prostate cancer cells. ${ }^{106}$ L Gao et al co-assembled thrombin aptamer and DTX on mesoporous silica NPs against tumor-cell proliferation. ${ }^{107} \mathrm{H}$ Gao's research group prepared DTX-loaded PEG-PCL NPs functionalized with GMT8, an aptamer with the highest affinity for U87 cells, for enhanced targeted glioblastoma therapy. ${ }^{108}$ The NPs significantly enhanced intracellular drug delivery and tumor spheroid penetration, could target glioblastoma and accumulated at the tumor site.

\section{Transferrin}

Transferrin (Tf), a polypeptide glycoprotein of approximately $80 \mathrm{kDa}$, has a high affinity for the Tf receptor which is ubiquitously expressed at low levels in most normal human tissues but at several fold higher in malignant cells. ${ }^{109}$ Zhai et al prepared Tf receptor-targeted liposomes composed of hydrogenated soy phosphatidylcholine, egg phosphatidylcholine, cholesterol and methoxy-poly(ethylene glycol) 2,000-distearoyl-phosphatidylethanolamine for DTX delivery. ${ }^{110}$ Tf receptor-targeted liposomes showed efficient uptake in K562 cells (Tf receptor +) and 3.6-fold greater cytotoxicity compared with non-targeted control liposomes in $\mathrm{KB}$ cells. Gan and Feng developed Tf-conjugated PLA-D- $\alpha-$ Tocopheryl polyethylene glycol succinate (PLA-TPGS) NPs loaded with DTX and coumarin 6 (a model imaging agent) for targeted delivery across the blood-brain barrier (BBB). ${ }^{111}$ Cellular uptake and cytotoxicity studies demonstrated that the Tf-conjugated PLA-TPGS NP formulation had great advantages over the original imaging/therapeutic agents. Moreover, the biodistribution investigation demonstrated that the Tf-conjugated PLA-TPGS NPs can deliver imaging/ therapeutic agents across the BBB to the brain.

\section{Hyaluronic acid}

Hyaluronic acid (HA), also called "hyaluronan", a natural linear polysaccharide composed of two alternating units of N-acetyl-D-glucosamine and D-glucuronic acid with a molecular weight of $10^{5}-10^{7}$, is abundant in the extracellular matrix and synovial fluids and has the advantages of biocompatibility and biodegradability. ${ }^{112} \mathrm{HA}$ can be specifically bound to cell-surface glycoprotein cluster determinant (CD44), which is overexpressed in various tumors, such as 
epithelial, stomach, ovarian, and colon cancers as well as in acute leukemia. ${ }^{113} \mathrm{HA}$ can be directly conjugated to an active cytotoxic agent to form a prodrug or used as a tumor-targeting moiety in drug delivery systems.

Cho's group conjugated HA with ceramide and used this and Pluronic ${ }^{\circledR}$ P85 to prepare self-assembled NPs for DTX delivery. ${ }^{48}$ The in vivo tumor-targeting efficiency of the HA-ceramide-based NPs was evaluated in the MCF-7 tumor-bearing mouse model using noninvasive fluorescence imaging. The results indicated that the fluorescence intensity in the tumors of the HA pre-injection group was lower than the no- pre-injection group after injection for 24 hours. This was due the HA pre-treatment blocking CD44 receptors and led to a reduction in cellular NP uptake.

\section{The pharmacokinetics, biodistribution and toxicity of DTX nanoformulations}

The enhanced therapeutic index of nanoscale DTX is based on the improved pharmacokinetics and biodistribution of DTX in this form compared with free DTX. Cellax, a formulation of DTX-carboxymethylcellulose NPs, has been reported to extend blood circulation time significantly compared with Taxotere, with a half-life 5.2 times longer, mean residence time (MRT) 7.3 times higher, area under the curve (AUC) 38.6 times higher, and substantially lower values for clearance $(2.5 \%)$ and volume of distribution (13.2\%). Compared with Taxotere, Cellax reduced the nonspecific distribution of DTX to the heart, lung and kidney by $48 \%, 90 \%$, and $90 \%$ at 3 hours, respectively, and induced no measurable toxicity at $170 \mathrm{mg}$ DTX/kg. In contrast, Taxotere displayed nonspecific uptake in all examined normal tissues and induced significant apoptosis in the lung and kidney at $40 \mathrm{mg}$ DTX/kg. ${ }^{34} \mathrm{Li}$ et al prepared folate-poly (PEG-cyanoacrylate-co-cholesteryl cyanoacrylate)-modified DTX-loaded liposomes (FAPDCT-L) for targeted chemotherapy. ${ }^{114}$ The results of their pharmacokinetic study indicated that the AUC of FA-PDCT-L increased 3.82 and 6.23 times in comparison with that of DTX-loaded liposomes and DTX solution, respectively. Meanwhile, FA-PDCT-L showed a longer retention time in the circulation and a lower DTX concentration in the liver and spleen, and greater drug accumulation in tumor tissue. The previously mentioned DTX-LNS, pLNS, and tLNS prepared by our group, in comparison to Duopafei, showed 1.31, 1.59 and 1.66 times greater AUC, respectively, and the MRT was significantly prolonged by about $1.91,2.40$ and 2.41 times, respectively, while clearance significantly decreased. ${ }^{59,62}$
Tumor, liver, spleen, and lung showed significantly higher DTX concentrations in the DTX-LNS, pLNS and tLNS groups compared with in the Duopafei group, while heart and kidney showed decreased DTX concentrations. The tumor targeting efficiency of tLNS was 1.13 times better than that of $\mathrm{pLNS}$. The in vivo antitumor efficacy studies on B16-tumor-bearing mice showed that DTX-LNS, pLNS, and tLNS exhibited higher antitumor efficacy by reducing tumor volume and less toxicity according to body weight variation analysis. The better antitumor efficacy of DTX nanoformulations was attributed to the improved pharmacokinetics such as increased AUC, longer MRT and decreased clearance, and increased drug accumulation in the tumor tissue.

\section{Issues to overcome before clinical and commercial application}

Overall, nanotechnology has played a great role in the delivery of DTX due to the unique nanosize (1-100 nm) and large surface-to-volume ratio. First, the water solubility of DTX can be significantly improved through conjugating it to nanomaterials or encapsulating it inside nanocarriers. Moreover, nanocarriers can improve the stability of DTX by protecting drugs from the surrounding environment, converting their pharmacokinetic properties to DTX, and lead to improved therapeutic efficacy. When intravenously injected into the body, nanoformulations can protect DTX from metabolizing enzymes until they were released and avoid its being rapidly cleared through the renal system due to their increased size compared with the free drug, thereby often resulting in a prolonged blood circulation time with an increased chance of accumulation in the target tissue. Nanoformulations can avoid side effects caused by the presence of P80, thus might render DTX more suitable for clinical utilization. In addition, nanocarriers can leak out of fenestrated tumor vascular walls and accumulate in the tumor tissue that frequently lacks effective lymphatic drainage by means of EPR-effect mediated passive targeting. Other tissues with leaky endothelial walls, including those of the liver, spleen and bone marrow, usually contribute to the uptake of nanocarriers. The macrophages residing in these tissues have been responsible for the major loss of injected nanocarriers. ${ }^{115}$ Modification of PEG on the surface of nanocarriers can reduce the uptake of the RES and prolong circulation time. Active targeting by modification with targeted ligands on the surface of nanocarriers can realize further tumor-cell targeting and increase the selective accumulation of DTX in tumors. Therefore, the adverse effects and systemic toxicity 
Table 3 Summary of nanoformulations for docetaxel (DTX) delivery over 2012-2013

\begin{tabular}{|c|c|c|c|c|}
\hline Nanoformulation & Type & Targeted ligand & Comment & Ref \\
\hline Metronomic SP5.2-DTX-NP & Nanoparticle & VEGFR-I & Mice & 116 \\
\hline $\begin{array}{l}\text { MR-contrasted DTX carboxymethylcellulose } \\
\text { nanoparticles }\end{array}$ & Nanoparticle & - & Mice & 117 \\
\hline $\begin{array}{l}\text { Core-shell nanoparticles through the self-assembly } \\
\text { of HPMA-based copolymers and degradable } \\
\text { polyester loaded with DTX and DOX }\end{array}$ & Nanoparticle & - & Mice & 118 \\
\hline Multilayer nanoparticles for DTX & Nanoparticle & - & Mice & 119 \\
\hline DTX-loaded mPEG-PCL nanoparticles & Nanoparticle & - & Mice & 120 \\
\hline Aptamer-functionalised PEG-PCL nanoparticles & Nanoparticle & Aptamer & Mice & 108 \\
\hline $\begin{array}{l}\text { PEGylated carboxymethylcellulose conjugate } \\
\left.\text { of DTX (Cellax }{ }^{T M}\right)\end{array}$ & Conjugate & - & Mice & 121 \\
\hline $\begin{array}{l}\text { TPGS-coated theranostic liposomes for co-delivery } \\
\text { of DTX and QDs }\end{array}$ & Liposome & FA & In vitro & 64 \\
\hline TPGS-coated liposomes & Liposome & Trastuzumab & In vitro & 122 \\
\hline F/TMSP-DTX-NLC & NLC & FA & Mice & 123 \\
\hline Beta-hydroxybutyric acid-grafted SLNs & SLN & Betreliesoxybutyric acid & Rats & 65 \\
\hline $\begin{array}{l}\text { TPGS based immunomicelles for co-delivery } \\
\text { of DTX and siRNA }\end{array}$ & Micelle & Herceptin & In vitro & 124 \\
\hline Amphiphilic micelles of poly(TMCC-co-LA)-g-PEG & Micelle & - & Mice & 125 \\
\hline DTX-loaded PI05/FI27 mixed micelles & Micelle & - & Mice & 126 \\
\hline C60-PEI-FA/DTX & Fullerene & FA & Mice & 127 \\
\hline Amorphous calcium phosphate porous nanospheres & Nanosphere & - & In vitro & 128 \\
\hline Polyarginine nanocapsules & Nanocapsule & - & In vitro & 129 \\
\hline PMAA chitosan hollow nanorods & Nanorod & - & In vitro & 130 \\
\hline Multiwalled carbon nanotube-DTX conjugate & Nanotube & - & In vitro & $|3|$ \\
\hline $\begin{array}{l}\text { Self-nanoemulsifying drug delivery system for the oral } \\
\text { administration of DTX }\end{array}$ & Nanoemulsion & - & Rats & 132 \\
\hline PLGA-coated silica nanorattle & Nanorattle & - & In vitro & 133 \\
\hline
\end{tabular}

Abbreviations: C60, fullerene; DOX, doxorubicin; FA, folic acid; HPMA, N-(2-hydroxypropyl) methacrylamide-based copolymers; MR, magnetic resonance; NLC, nanostructured lipid carrier; NP, nanoparticle; PEI, polyethylenimine; PLGA, poly(lactic-co-glycolic acid); PMAA, polymethacrylic acid; poly(TMCC-co-LA)-g-PEG, poly(2methyl-2-carboxytrimethylene carbonate-co-D,L-lactide)-graft-poly(ethylene glycol); QDs, quantum dots; SLN, solid lipid nanoparticle; TMSP, tumor microenvironmentsensitive polypeptides; TPGS, D-alpha-tocopheryl polyethylene glycol 1000 succinate.

of DTX can be reduced and therapeutic efficacy improved significantly due to the application of nanotechnology in drug delivery.

Significant efforts have been made and considerable progress made in the delivery of DTX; however, Taxotere remains the only commercial formulation available for clinical use. Studies of nanoformulations for DTX delivery over 2012-2013 are summarized in Table 3. As shown in the table, most of the current research is still at the laboratory stage and in animal models. Nevertheless, it is exciting to

Table 4 Summary of nanoformulations for docetaxel (DTX) in clinical development

\begin{tabular}{|c|c|c|c|c|}
\hline Name & Type of nanoformulation & Developer & Status & Ref \\
\hline BIND-0I4 & $\begin{array}{l}\text { PEG-PLGA nanoparticles } \\
\text { (Cambridge, MA, USA) }\end{array}$ & $\begin{array}{l}\text { BIND Therapeutics } \\
\text { (Cambridge, MA, USA) }\end{array}$ & Phase I & 26 \\
\hline DTX-PNP & Polymeric nanoparticles & $\begin{array}{l}\text { Samyang Pharmceuticals } \\
\text { (Seoul, Korea) }\end{array}$ & Phase I & 27 \\
\hline NKTR-I05 & PEG-DTX conjugates & $\begin{array}{l}\text { Nektar Therapeutics } \\
\text { (San Francisco, CA, USA) }\end{array}$ & Phase I & 33 \\
\hline LE-DT & Liposomes & NeoPharm, Inc (Lake Forrest, IL, USA) & Phase I & 52 \\
\hline ATI-II 23 & Liposomes & Azaya Therapeutics (San Antonio, TX, USA) & Phase I & 134 \\
\hline ANX-5I4 & Injectable emulsion & Mast Therapeutics, Inc (San Diego, CA, USA) & Phase I & 135 \\
\hline Dendrimer-DTX & Dendrimers & Sylvania Platinum Ltd (Hamilton, Bermuda) & $\begin{array}{l}\text { Approved to carry on } \\
\text { a Phase I/II clinical trial }\end{array}$ & 2 \\
\hline
\end{tabular}

Abbreviations: PEG, poly(ethylene glycol); PLGA, poly(lactic-co-glycolic acid). 
see that several DTX nanoformulations have been in clinical trials and are expected to be developed for the market, as summarized in Table 4. However, for the transformation of DTX-loaded nanoformulations from research into clinical products to be realized, requires a number of issues to be overcome. Studies in these areas must be carried out to accelerate the development of commercial DTX-loaded nanoformulations.

\section{Safety concerns}

Most of the current studies on DTX-loaded nanoformulations have evaluated in vivo antitumor efficacy and distribution in small animal models; less research on the metabolism, excretion, and acute and chronic toxicity in vivo has been reported. Further, there is also a lack of research on the safety of the novel synthesized materials used for DTX-loaded nanoformulations.

\section{Manufacturing problems}

As a great number of DTX-loaded nanoformulations have been prepared only at the laboratory scale due to their complicated process and high cost, much effort still needs to be made before large-scale production and commercialization can be achieved.

\section{Quality control}

Consistent particle diameter and distribution of particle size, physical and chemical stability, removal of the organic solvents in production, sufficient drug loading and the surface characteristics must be guaranteed reliably.

\section{Improving patient compliance}

To achieve better patient compliance for clinical administration, issues related to the clinical application must be considered in the design of DTX-loaded nanoformulations; for example, lower drug cost, dosage forms that are simple to use, reducing the frequency of administration and decreasing side effects.

\section{Conclusion}

DTX has been widely used in the clinical treatment of various types of tumors in the last decade. However, its poor water solubility and non-selective distribution limit the clinical dose and bring great side effects to normal tissues. As reviewed herein, significant efforts and tremendous progress have been made in the delivery of DTX for cancer therapy in the past decade. Many drug delivery systems have been developed for the effective delivery of DTX, such as polymer-based, lipid-based, lipid-polymer hybrid nanocarriers, dendrimers as well as inorganic NPs. To achieve greater tumor-cell targeting, active targeting has been carried out extensively as reviewed. Overall, nanotechnology holds great potential for DTX delivery due to the advantages of nanometer-size, ability to increase water solubility, effective selectivity to tumor cells, controlled drug release, desirable pharmacokinetic properties, ability to minimize side effects, and so on.

However, there is no DTX nanoformulation currently commercially available and there remain many barriers and challenges, including safety concerns, manufacturing problems, quality control issues and the importance of improving patient compliance. These need to be overcome and further research is required before clinical and commercial application of DTX-loaded nanoformulations can be realized.

\section{Disclosure}

The authors report no conflicts of interest in this work.

\section{References}

1. Denis JN, Greene AE, Guenard D, Gueritte-Voegelein F, Mangatal L, Potier P. Highly efficient, practical approach to natural taxol. JAm Chem Soc. 1988;110(17):5917-5919.

2. Tan Q, Liu X, Fu X, Li Q, Dou J, Zhai G. Current development in nanoformulations of docetaxel. Expert Opin Drug Deliv. 2012;9(8):975-990.

3. Montero A, Fossella F, Hortobagyi G, Valero V. Docetaxel for treatment of solid tumours: a systematic review of clinical data. Lancet Oncol. 2005;6(4):229-239.

4. Gueritte-Voegelein F, Guenard D, Lavelle F, Le Goff MT, Mangatal L, Potier P. Relationships between the structure of taxol analogs and their antimitotic activity. J Med Chem. 1991;34(3):992-998.

5. Zhao P, Astruc D. Docetaxel nanotechnology in anticancer therapy. Chem Med Chem. 2012;7(6):952-972.

6. Engels FK, Mathot RAA, Verweij J. Alternative drug formulations of docetaxel: a review. Anti-Cancer Drug. 2007;18(2):95-103.

7. Catimel G, Verweij J, Mattijssen V, et al. Docetaxel (Taxotere ${ }^{\circledR}$ ): an active drug for the treatment of patients with advanced squamous cell carcinoma of the head and neck. Ann Oncol. 1994;5(6):533-537.

8. Valero V, Holmes FA, Walters RS, et al. Phase II trial of docetaxel: a new, highly effective antineoplastic agent in the management of patients with anthracycline-resistant metastatic breast cancer. J Clin Oncol. 1995;13(12):2886-2894.

9. Baker J, Ajani J, Scotté F, et al. Docetaxel-related side effects and their management. Eur J Oncol Nurs. 2009;13(1):49-59.

10. Eckhoff L, Nielsen M, Moeller S, Knoop A. TAXTOX-a retrospective study regarding the side effects of docetaxel given as part of the adjuvant treatment to patients with primary breast cancer in Denmark from 2007 to 2009. Acta Oncol. 2011;50(7):1075-1082.

11. Roglio I, Bianchi R, Camozzi F, et al. Docetaxel-induced peripheral neuropathy: protective effects of dihydroprogesterone and progesterone in an experimental model. J Peripher Nerv Syst. 2009;14(1):36-44.

12. Verweij J, Catimel G, Sulkes A, et al. Phase II studies of docetaxel in the treatment of various solid tumours. Eur J Cancer. 1995;31(Suppl 4):S21-S24.

13. Yanasarn N, Sloat BR, Cui Z. Nanoparticles engineered from lecithinin-water emulsions as a potential delivery system for docetaxel. Int $J$ Pharm. 2009;379(1):174-180.

14. Thiesen J, Krämer I. Physico-chemical stability of docetaxel premix solution and docetaxel infusion solutions in PVC bags and polyolefine containers. Pharm World Sci. 1999;21(3):137-141. 
15. Hart M, Acott S. Physical and chemical stability of Taxotere ${ }^{\circledR}$ (docetaxel) one-vial $(20 \mathrm{mg} / \mathrm{mL})$ infusion solution following refrigerated storage. Ecancermedicalscience. 2010;4:202.

16. Vasey PA, Kaye SB, Morrison R, et al. Phase I clinical and pharmacokinetic study of PK1 [N-(2-hydroxypropyl) methacrylamide copolymer doxorubicin]: first member of a new class of chemotherapeutic agents - drug-polymer conjugates. Clin Cancer Res. 1999;5(1):83-94.

17. Liu Z, Wang Y, Zhang N. Micelle-like nanoassemblies based on polymer-drug conjugates as an emerging platform for drug delivery. Expert Opin Drug Deliv. 2012;9(7):805-822.

18. Mu CF, Balakrishnan P, Cui FD, et al. The effects of mixed MPEGPLA/Pluronic ${ }^{\circledR}$ copolymer micelles on the bioavailability and multidrug resistance of docetaxel. Biomaterials. 2010;31(8):2371-2379.

19. Zheng Y, Huang L, Mei L. Docetaxel-loaded TPGS-b-(PLA-ranPGA) nanoparticles for cervix cancer treatment. Paper presented at: Bioinformatics and Biomedical Engineering, (iCBBE) 2011 5th International Conference on 2011.

20. Etrych T, Š́rová M, Starovoytova L, Ríhová B, Ulbrich K. HPMA copolymer conjugates of paclitaxel and docetaxel with $\mathrm{pH}$-controlled drug release. Mol Pharm. 2010;7(4):1015-1026.

21. Hwang HY, Kim IS, Kwon IC, Kim YH. Tumor targetability and antitumor effect of docetaxel-loaded hydrophobically modified glycol chitosan nanoparticles. J Control Release. 2008;128(1):23-31.

22. Kataoka K, Harada A, Nagasaki Y. Block copolymer micelles for drug delivery: design, characterization and biological significance. Adv Drug Deliv Rev. 2001;47(1):113-131.

23. Elsabahy M, Perron M, Bertrand N, Yu G, Leroux J. Solubilization of docetaxel in poly (ethylene oxide)-block-poly (butylene/styrene oxide) micelles. Biomacromolecules. 2007;8(7):2250-2257.

24. Mikhail AS, Allen C. Poly (ethylene glycol)-b-poly ( $\varepsilon$-caprolactone) micelles containing chemically conjugated and physically entrapped docetaxel: synthesis, characterization, and the influence of the drug on micelle morphology. Biomacromolecules. 2010;11(5):1273-1280.

25. Elsabahy M, Wooley KL. Design of polymeric nanoparticles for biomedical delivery applications. Chem Soc Rev. 2012;41(7):2545-2561.

26. Wang AZ, Langer R, Farokhzad OC. Nanoparticle delivery of cancer drugs. Annu Rev Med. 2012;63:185-198.

27. Svenson S. Clinical translation of nanomedicines. Curr Opin Solid State Mater Sci. 2012;16(6):287-294.

28. Deng C, Jiang Y, Cheng R, Meng F, Zhong Z. Biodegradable polymeric micelles for targeted and controlled anticancer drug delivery: promises, progress and prospects. Nano Today. 2012;7(5):467-480.

29. Sanna V, Sechi M. Nanoparticle therapeutics for prostate cancer treatment. Nanomedicine. 2012;8(Suppl 1):S31-S36.

30. Lammers T, Kiessling F, Hennink WE, Storm G. Drug targeting to tumors: principles, pitfalls and (pre-) clinical progress. J Control Release. 2012;161(2):175-187.

31. Conte C, Ungaro F, Maglio G, et al. Biodegradable core-shell nanoassemblies for the delivery of docetaxel and $\mathrm{Zn}$ (II)-phthalocyanine inspired by combination therapy for cancer. $J$ Control Release. 2013;167(1):40-52.

32. Khandare J, Minko T. Polymer-drug conjugates: progress in polymeric prodrugs. Prog Polym Sci. 2006;31(4):359-397.

33. Vicent MJ, Ringsdorf H, Duncan R. Polymer therapeutics: clinical applications and challenges for development. Adv Drug Deliv Rev. 2009;61(13):1117-1120

34. Ernsting MJ, Tang WL, MacCallum NW, Li SD. Preclinical pharmacokinetic, biodistribution, and anti-cancer efficacy studies of a docetaxel-carboxymethylcellulose nanoparticle in mouse models. Biomaterials. 2012;33(5):1445-1454.

35. Lee E, Kim H, Lee IH, Jon S. In vivo antitumor effects of chitosanconjugated docetaxel after oral administration. J Control Release. 2009;140(2):79-85.

36. Buhleier E, Wehner W, Vögtle F. Cascade and nonskid-chain-like synthesis of molecular cavity topologies. Synthesis. 1978;2:155-158.

37. Dykes GM. Dendrimers: a review of their appeal and applications. J Chem Technol Biotechnol. 2001;76(9):903-918.
38. Nanjwade BK, Bechra HM, Derkar GK, Manvi F, Nanjwade VK. Dendrimers: emerging polymers for drug-delivery systems. Eur J Pharm Sci. 2009;38(3):185-196.

39. Tomalia DA. Starburstr dendrimers - Nanoscopic supermolecules according to dendritic rules and principles. Macromol Symp.1996; 101(1):243-255

40. Hawker CJ, Frechet JM. Preparation of polymers with controlled molecular architecture. A new convergent approach to dendritic macromolecules. J Am Chem Soc. 1990;112(21):7638-7647.

41. Paleos CM, Tsiourvas D, Sideratou Z, Tziveleka LA. Drug delivery using multifunctional dendrimers and hyperbranched polymers. Expert Opin Drug Deliv. 2010;7(12):1387-1398.

42. Svenson S. Dendrimers as versatile platform in drug delivery applications. Eur J Pharm Biopharm. 2009;71(3):445-462.

43. Nayak AK, Dhara AK. Nanotechnology in drug delivery applications: a review. Arch Appl Sci Res. 2010;2(2):284-293.

44. Gajbhiye V, Jain NK. The treatment of Glioblastoma Xenografts by surfactant conjugated dendritic nanoconjugates. Biomaterials. 2011;32(26):6213-6225.

45. MiY, Liu Y, Feng S-S. Formulation of Docetaxel by folic acid-conjugated

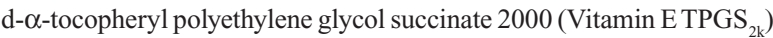
micelles for targeted and synergistic chemotherapy. Biomaterials. 2011;32(16):4058-4066.

46. Lee SW, Yun MH, Jeong SW, et al. Development of docetaxel-loaded intravenous formulation, Nanoxel-PM ${ }^{\mathrm{TM}}$ using polymer-based delivery system. J Control Release. 2011;155(2):262-271.

47. Chaudhari KR, Kumar A, Khandelwal VKM, Mishra AK, Monkkonen J, Murthy RSR. Targeting efficiency and biodistribution of zoledronate conjugated docetaxel loaded pegylated PBCA nanoparticles for bone metastasis. Adv Funct Mater. 2012;22(19):4101-4114.

48. Cho H-J, Yoon HY, Koo H, et al. Self-assembled nanoparticles based on hyaluronic acid-ceramide (HA-CE) and Pluronic ${ }^{\circledR}$ for tumor-targeted delivery of docetaxel. Biomaterials. 2011;32(29):7181-7190.

49. Porter CJH, Pouton CW, Cuine JF, Charman WN. Enhancing intestinal drug solubilisation using lipid-based delivery systems. Adv Drug Deliv Rev. 2008;60(6):673-691.

50. Beg S, Swain S, Rizwan M, Irfanuddin M, Shobha Malini D. Bioavailability enhancement strategies: basics, formulation approaches and regulatory considerations. Curr Drug Deliv. 2011;8(6):691-702.

51. Malam Y, Loizidou M, Seifalian AM. Liposomes and nanoparticles: nanosized vehicles for drug delivery in cancer. Trends Pharmacol Sci. 2009;30(11):592-599.

52. Deeken JF, Slack R, Weiss GJ, et al. A phase I study of liposomalencapsulated docetaxel (LE-DT) in patients with advanced solid tumor malignancies. Cancer Chemother Pharmcol. 2013;71(3):627-633.

53. Mohanraj V, Chen Y. Nanoparticles-a review. Tropical Journal of Pharmaceutical Research. 2006;5(1):561-573.

54. Bamrungsap S, Zhao Z, Chen T, et al. Nanotechnology in therapeutics: a focus on nanoparticles as a drug delivery system. Nanomedicine. 2012;7(8):1253-1271.

55. Mehnert W, Mäder K. Solid lipid nanoparticles production, characterization and applications. Adv Drug Deliv Rev. 2001;47(2): $165-196$.

56. Xu Z, Chen L, Gu W, et al. The performance of docetaxel-loaded solid lipid nanoparticles targeted to hepatocellular carcinoma. Biomaterials. 2009;30(2):226-232.

57. Das S, Ng WK, Tan RBH. Are nanostructured lipid carriers (NLCs) better than solid lipid nanoparticles (SLNs): development, characterizations and comparative evaluations of clotrimazole-loaded SLNs and NLCs? Eur J Pharm Sci. 2012;47(1):139-151.

58. Liu D, Liu F, Liu Z, Wang L, Zhang N. Tumor specific delivery and therapy by double-targeted nanostructured lipid carriers with antiVEGFR-2 antibody. Mol Pharm. 2011;8(6):2291-2301.

59. Wang L, Liu Z, Liu D, Liu C, Juan Z, Zhang N. Docetaxel-loadedlipid-based-nanosuspensions (DTX-LNS): preparation, pharmacokinetics, tissue distribution and antitumor activity. Int J Pharm. 2011;413(1):194-201 
60. Lim SB, Banerjee A, Önyüksel H. Improvement of drug safety by the use of lipid-based nanocarriers. J Control Release. 2012;163(1):34-45.

61. Liu Y, Xie P, Zhang D, Zhang Q. A mini review of nanosuspensions development. J Drug Target. 2012;20(3):209-223.

62. Wang L, Li M, Zhang N. Folate-targeted docetaxel-lipid-based-nanosuspensions for active-targeted cancer therapy. Int J Nanomedicine. 2012;7:3281-3294.

63. Muthu MS, Kulkarni SA, Xiong J, Feng S-S. Vitamin E TPGS coated liposomes enhanced cellular uptake and cytotoxicity of docetaxel in brain cancer cells. Int J Pharm. 2011;421(2):332-340.

64. Muthu MS, Kulkarni SA, Raju A, Feng S-S. Theranostic liposomes of TPGS coating for targeted co-delivery of docetaxel and quantum dots. Biomaterials. 2012;33(12):3494-3501.

65. Venishetty VK, Samala R, Komuravelli R, Kuncha M, Sistla R, Diwan PV. $\beta$-hydroxybutyric acid grafted solid lipid nanoparticles: a novel strategy to improve drug delivery to brain. Nanomedicine. 2013;9(3):388-397.

66. Zhao X, Zhao Y, Geng L, et al. Pharmacokinetics and tissue distribution of docetaxel by liquid chromatography-mass spectrometry: evaluation of folate receptor-targeting amphiphilic copolymer modified nanostructured lipid carrier. J Chromatogr B. 2011;879(31):3721-3727.

67. Fang RH, Zhang L. Dispersion-based methods for the engineering and manufacture of polymeric nanoparticles for drug delivery applications. Journal of Nanoengineering and Nanomanufacturing. 2011;1(1):106-112.

68. Cheow WS, Hadinoto K. Factors affecting drug encapsulation and stability of lipid-polymer hybrid nanoparticles. Colloids Surf B Biointerfaces. 2011;85(2):214-220.

69. Tan S, Li X, Guo Y, Zhang Z. Lipid-enveloped hybrid nanoparticles for drug delivery. Nanoscale. 2013;5:860-872.

70. Zhang L, Zhang L. Lipid-polymer hybrid nanoparticles: synthesis, characterization and applications. Nano Life. 2010;1(01\&02):163-173.

71. Wong HL, Rauth AM, Bendayan R, Wu XY. In vivo evaluation of a new polymer-lipid hybrid nanoparticle (PLN) formulation of doxorubicin in a murine solid tumor model. Eur J Pharm Biopharm. 2007;65(3): 300-308.

72. Liu Y, Li K, Pan J, Liu B, Feng SS. Folic acid conjugated nanoparticles of mixed lipid monolayer shell and biodegradable polymer core for targeted delivery of Docetaxel. Biomaterials. 2010;31(2):330-338.

73. Bershteyn A, Chaparro J, Yau R, et al. Polymer-supported lipid shells, onions, and flowers. Soft matter. 2008;4(9):1787-1791.

74. Douroumis D. Mesoporous silica nanoparticles as drug delivery system. J Nanomed Nanotechnol. 2011;2:3.

75. Mamaeva V, Sahlgren C, Lindén M. Mesoporous silica nanoparticles in medicine-recent advances. Adv Drug Deliv Rev. 2012.

76. Slowing II, Vivero-Escoto JL, Wu CW, Lin VSY. Mesoporous silica nanoparticles as controlled release drug delivery and gene transfection carriers. Adv Drug Deliv Rev. 2008;60(11):1278-1288.

77. He Q, Shi J. Mesoporous silica nanoparticle based nano drug delivery systems: synthesis, controlled drug release and delivery, pharmacokinetics and biocompatibility. J Mater Chem. 2011;21(16): $5845-5855$.

78. Sun JT, Hong CY, Pan CY. Fabrication of PDEAEMA-coated mesoporous silica nanoparticles and $\mathrm{pH}$-responsive controlled release. J Phys Chem C. 2010;114(29):12481-12486.

79. Lebret V, Raehm L, Durand JO, et al. Folic acid-targeted mesoporous silica nanoparticles for two-photon fluorescence. J Biomed Nanotechnol. 2010;6(2):176-180.

80. Li L, Tang F, Liu H, et al. In vivo delivery of silica nanorattle encapsulated docetaxel for liver cancer therapy with low toxicity and high efficacy. Acs Nano. 2010;4(11):6874-6882.

81. Chen Y, Chen H, Ma M, et al. Double mesoporous silica shelled spherical/ellipsoidal nanostructures: synthesis and hydrophilic/ hydrophobic anticancer drug delivery. J Mater Chem. 2011;21(14): 5290-5298.

82. Ghosh P, Han G, De M, Kim CK, Rotello VM. Gold nanoparticles in delivery applications. Adv Drug Deliv Rev. 2008;60(11):1307-1315.
83. Khlebtsov N, Dykman L. Biodistribution and toxicity of engineered gold nanoparticles: a review of in vitro and in vivo studies. Chem Soc Rev. 2011;40(3):1647-1671.

84. François A, Laroche A, Pinaud N, et al. Encapsulation of docetaxel into PEGylated gold nanoparticles for vectorization to cancer cells. Chem Med Chem. 2011;6(11):2003-2008.

85. Fang J, Nakamura H, Maeda H. The EPR effect: unique features of tumor blood vessels for drug delivery, factors involved, and limitations and augmentation of the effect. Adv Drug Deliv Rev. 2011;63(3): $136-151$.

86. Matsumura Y, Maeda H. A new concept for macromolecular therapeutics in cancer chemotherapy: mechanism of tumoritropic accumulation of proteins and the antitumor agent smancs. Cancer Res. 1986;46(12 Part 1):6387-6392.

87. Torchilin V. Tumor delivery of macromolecular drugs based on the EPR effect. Adv Drug Delivery Rev. 2011;63(3):131-135.

88. Danhier F, Feron O, Préat V. To exploit the tumor microenvironment: passive and active tumor targeting of nanocarriers for anti-cancer drug delivery. J Control Release. 2010;148(2):135-146.

89. Schrama D, Reisfeld RA, Becker JC. Antibody targeted drugs as cancer therapeutics. Nat Rev Drug Discov. 2006;5(2):147-159.

90. Yu B, Zhao X, Lee LJ, Lee RJ. Targeted delivery systems for oligonucleotide therapeutics. AAPS J. 2009;11(1):195-203.

91. Liu Y, Li K, Liu B, Feng SS. A strategy for precision engineering of nanoparticles of biodegradable copolymers for quantitative control of targeted drug delivery. Biomaterials. 2010;31(35): 9145-9155.

92. Pangburn TO, Petersen MA, Waybrant B, Adil MM, Kokkoli E. Peptide-and aptamer-functionalized nanovectors for targeted delivery of therapeutics. J Biomech Eng. 2009;131(7):074005.

93. Wang X, Wang Y, Chen X, Wang J, Zhang X, Zhang Q. NGR-modified micelles enhance their interaction with CD13-overexpressing tumor and endothelial cells. $J$ Control Release. 2009;139(1):56-62.

94. Zhang Y, Wang X, Wang J, Zhang X, Zhang Q. Octreotide-modified polymeric micelles as potential carriers for targeted docetaxel delivery to somatostatin receptor overexpressing tumor cells. Pharmaceut Res. 2011;28(5):1167-1178.

95. Xie Z, Hu X, Chen X, Lu T, Liu S, Jing X. A biodegradable diblcok copolymer poly (ethylene glycol)-block-poly (L-lactide-co-2-methyl2-carboxyl-propylene carbonate): docetaxel and RGD conjugation. J Appl Polym Sci. 2008;110(5):2961-2970.

96. Naik S, Patel D, Chuttani K, Mishra AK, Misra A. In vitro mechanistic study of cell death and in vivo performance evaluation of RGD grafted PEGylated docetaxel liposomes in breast cancer. Nanomedicine. 2012;8(6):951-962.

97. Ray A, Larson N, Pike DB, et al. Comparison of active and passive targeting of docetaxel for prostate cancer therapy by HPMA copolymerRGDfK conjugates. Mol Pharm. 2011;8(4):1090-1099.

98. Lu Y, Low PS. Folate-mediated delivery of macromolecular anticancer therapeutic agents. Adv Drug Deliv Rev. 2002;54(5):675-693.

99. Zhang Z, Jia J, Lai Y, Ma Y, Weng J, Sun L. Conjugating folic acid to gold nanoparticles through glutathione for targeting and detecting cancer cells. Bioorgan Med Chem. 2010;18(15):5528-5534.

100. Zhang Y, Chen T. Targeting nanomaterials: future drugs for cancer chemotherapy. Int J Nanomedicine. 2012;7:5283-5286.

101. Zhang Y, Hong H, Cai W. Tumor-targeted drug delivery with Aptamers. Curr Med Chem. 2011;18(27):4185-4194.

102. Zhou J, Rossi JJ. Cell-specific aptamer-mediated targeted drug delivery. Oligonucleotides. 2011;21(1):1-10.

103. Dausse E, Da Rocha Gomes S, Toulmé JJ. Aptamers: a new class of oligonucleotides in the drug discovery pipeline? Curr Opin Pharmacol. 2009;9(5):602-607.

104. Dua P, Kim S, Lee D. Nucleic acid aptamers targeting cell-surface proteins. Methods. 2011;54(2):215-225.

105. Missailidis S, Hardy A. Aptamers as inhibitors of target proteins. Expert Opin Ther Pat. 2009;19(8):1073-1082. 
106. Cheng J, Teply BA, Sherifi I, et al. Formulation of functionalized PLGA-PEG nanoparticles for in vivo targeted drug delivery. Biomaterials. 2007;28(5):869-876.

107. Gao L, Cui Y, He Q, Yang Y, Fei J, Li J. Selective recognition of co-assembled thrombin aptamer and docetaxel on mesoporous silica nanoparticles against tumor cell proliferation. Chem-Eur J. 2011;17(47):13170-13174.

108. Gao H, Qian J, Yang Z, et al. Whole-cell SELEX aptamer-functionalised poly (ethyleneglycol)-poly ( $\varepsilon$-caprolactone) nanoparticles for enhanced targeted glioblastoma therapy. Biomaterials. 2012;33: 6264-6272.

109. Daniels TR, Bernabeu E, Rodríguez JA, et al. The transferrin receptor and the targeted delivery of therapeutic agents against cancer. Biochim Biophys Acta. 2012;1820(3):291-317.

110. Zhai G, Wu J, Yu B, Guo C, Yang X, Lee RJ. A transferrin receptortargeted liposomal formulation for docetaxel. J Nanosci Nanotechnol. 2010;10(8):5129-5136

111. Gan CW, Feng SS. Transferrin-conjugated nanoparticles of poly (lactide)-d- $\alpha$-Tocopheryl polyethylene glycol succinate diblock copolymer for targeted drug delivery across the blood-brain barrier. Biomaterials. 2010;31(30):7748-7757.

112. Choi KY, Chung H, Min KH, et al. Self-assembled hyaluronic acid nanoparticles for active tumor targeting. Biomaterials. 2010;31(1): 106-114.

113. Oh EJ, Park K, Kim KS, et al. Target specific and long-acting delivery of protein, peptide, and nucleotide therapeutics using hyaluronic acid derivatives. J Controlled Release. 2010;141(1):2-12.

114. Li X, Tian X, Zhang J, et al. In vitro and in vivo evaluation of folate receptor-targeting amphiphilic copolymer-modified liposomes loaded with docetaxel. Int J Nanomedicine. 2011;6:1167-1184.

115. Li S-D, Huang L. Pharmacokinetics and biodistribution of nanoparticles. Mol Pharm. 2008;5(4):496-504.

116. Yu D-H, Ban F-Q, Zhao M, et al. The use of nanoparticulate delivery systems in metronomic chemotherapy. Biomaterials. 2013;34(16): 3925-3937.

117. Ernsting MJ, Foltz WD, Undzys E, Tagami T, Li S-D. Tumor-targeted drug delivery using MR-contrasted docetaxel-carboxymethylcellulose nanoparticles. Biomaterials. 2012;33(15):3931-3941.

118. Jäger E, Jäger A, Chytil $P$, et al. Combination chemotherapy using core-shell nanoparticles through the self-assembly of HPMA-based copolymers and degradable polyester. J Control Release. 2013;165(2): 153-161.

119. Oh KS, Lee H, Kim JY, et al. The multilayer nanoparticles formed by layer by layer approach for cancer-targeting therapy. J Control Release. 2013;165(1):9-15.

120. Liu Q, Li R, Zhu Z, et al. Enhanced antitumor efficacy, biodistribution and penetration of docetaxel-loaded biodegradable nanoparticles. Int J Pharm. 2012;430(1-2):350-358.

121. Ernsting MJ, Murakami M, Undzys E, Aman A, Press B, Li S-D. A docetaxel-carboxymethylcellulose nanoparticle outperforms the approved taxane nanoformulation, Abraxane, in mouse tumor models with significant control of metastases. J Control Release. 2012;162(3): $575-581$.
122. Raju A, Muthu MS, Feng S-S. Trastuzumab-conjugated vitamin E TPGS liposomes for sustained and targeted delivery of docetaxel. Expert Opin Drug Deliv. 2013;10(6):747-760.

123. Gao W, Xiang B, Meng T-T, Liu F, Qi X-R. Chemotherapeutic drug delivery to cancer cells using a combination of folate targeting and tumor microenvironment-sensitive polypeptides. Biomaterials. 2013;34(16):4137-4139.

124. Zhao J, Mi Y, Feng S-S. Targeted co-delivery of docetaxel and siPlk1 by herceptin-conjugated vitamin E TPGS based immunomicelles. Biomaterials. 2013;34(13):3411-3421.

125. Ho KS, Aman AM, Al-awar RS, Shoichet MS. Amphiphilic micelles of poly(2-methyl-2-carboxytrimethylene carbonate-co-D,L-lactide)graft-poly(ethylene glycol) for anti-cancer drug delivery to solid tumours. Biomaterials. 2012;33(7):2223-2229.

126. Chen L, Sha X, Jiang X, Chen Y, Ren Q, Fang X. Pluronic P105/ F127 mixed micelles for the delivery of docetaxel against taxolresistant non-small cell lung cancer: optimization and in vitro, in vivo evaluation. Int J Nanomedicine. 2013;8:73-84.

127. Shi J, Zhang H, Wang L, et al. PEI-derivatized fullerene drug delivery using folate as a homing device targeting to tumor. Biomaterials. 2013;34(1):251-261.

128. Qi C, Zhu YJ, Zhao XY, et al. Highly stable amorphous calcium phosphate porous nanospheres: microwave-assisted rapid synthesis using ATP as phosphorus source and stabilizer, and their application in anticancer drug delivery. Chem-Eur J. 2013;19(3):981-987.

129. Lozano M, Lollo G, Alonso-Nocelo M, et al. Polyarginine nanocapsules: a new platform for intracellular drug delivery. J Nanopart Res. 2013;15:1515.

130. Sun YJ, Dong WB, Wang HY, et al. Template synthesis of PMAA@ chitosan hollow nanorods for docetaxel delivery. Polym Chem. 2013;4(8):2489-2495.

131. Arora S, Saharan R, Kaur H, Kaur I, Bubber P, Bharadwaj LM. Attachment of docetaxel to multiwalled carbon nanotubes for drug Delivery applications. Adv Sci Lett. 2012;17(1):70-75.

132. Quan Q, Kim D-W, Marasini N, et al. Physicochemical characterization and in vivo evaluation of solid self-nanoemulsifying drug delivery system for oral administration of docetaxel. J Microencapsul. 2013;30(4):307-314.

133. Li L, Zhang Y, Hao N, Chen D, Tang F. Fabrication of PLGA coated silica nanorattle for controlling the drug release behavior. $\mathrm{Chin} \mathrm{Sci}$ Bull. 2012;57(27):3631-3638.

134. Puri A, Loomis K, Smith B, et al. Lipid-based nanoparticles as pharmaceutical drug carriers: from concepts to clinic. Crit Rev Ther Drug Carrier Syst. 2009;26(6):523-580

135. Ma X, Zhao Y, Liang X-J. Theranostic nanoparticles engineered for clinic and pharmaceutics. Acc Chem Res. 2011;44(10):1114-1122.
International Journal of Nanomedicine

\section{Publish your work in this journal}

The International Journal of Nanomedicine is an international, peerreviewed journal focusing on the application of nanotechnology in diagnostics, therapeutics, and drug delivery systems throughout the biomedical field. This journal is indexed on PubMed Central,

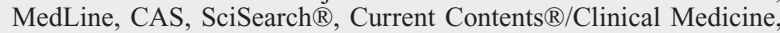

\section{Dovepress}

Journal Citation Reports/Science Edition, EMBase, Scopus and the Elsevier Bibliographic databases. The manuscript management system is completely online and includes a very quick and fair peer-review system, which is all easy to use. Visit http://www.dovepress.com/ testimonials.php to read real quotes from published authors. 